\title{
Possible Mechanism and Current Recommendation of Thromboembolism in COVID-19
}

\author{
Dita Aulia Rachmi, Eka Prasetya Budi Mulia, Johanes Nugroho* \\ Department of Cardiology and Vascular Medicine, Faculty of Medicine Universitas Airlangga - Dr. Soetomo General Hospital, \\ Surabaya, Indonesia
}

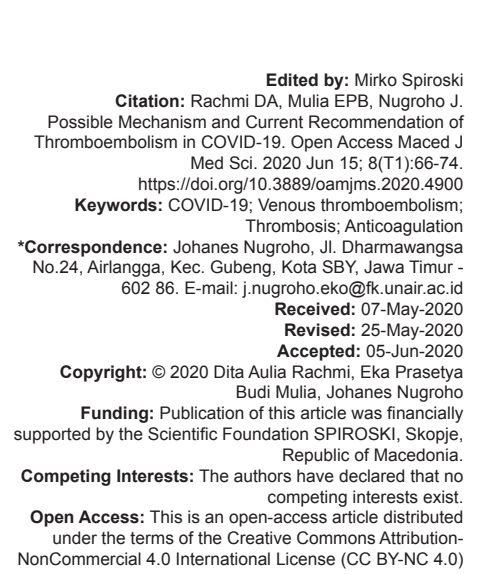

Introduction

The coronavirus disease (COVID-19) has become a global pandemic. Since December 2019, the total number worldwide of confirmed cases is $2,356,414$ with mortality rate $6.8 \%$ involving 213 countries all over the world (WHO data April 21, 2020) [1]. The first two COVID-19 patients in Indonesia were reported on March 2, 2020. As per April 21, 2020, the total cases of COVID-19 reached 6760 positive cases, of which 590 had died. The mortality rate in Indonesia was as much as $8.7 \%$, and it was the highest rate in Southeast Asia [2].

Study of epidemiology and clinical characteristics of COVID-19 patients have started to unfold. On the other hand, the mortality risk factors and the exact clinical course of disease, including shedding of the coronavirus, have not been well described. The clinical spectrum of COVID-19 ranges from mild to critically ill cases. The clinical spectrum of COVID-19 consists of mild to critical illness. The previous studies revealed that old age, increased SOFA scores, greater d-dimers level more than $1000 \mathrm{ng} / \mathrm{mL}$, and those who have pre-existing comorbidities are more likely to have a poor prognosis [3], [4]. Patient with COVID-19 who fell into severe or critical condition is exposed to venous thromboembolism potential risk factors such as infection, immobilization, respiratory failure, hypoxia, mechanical ventilation, and use of central venous catheter (CVC) [5].

Three cases in China showed antiphospholipid autoimmune response in patients with COVID-19. These findings give rise to coagulopathy roles in extensive thromboembolism in patients with COVID19 [6]. The prognosis of COVID patients, once they are complicated with DVT or fatal pulmonary emboli, will significantly decline [5], [7], [8].

This article was aimed to summarize the current literature of mechanism and recommendation in thromboembolism related COVID-19 patients.

\section{Epidemiology}

Venous thromboembolic events (VTE) discussed in this article include deep vein thrombosis (DVT) and pulmonary embolism (PE). Epidemiology data regarding these events in COVID-19 were still very limited. The prevalence of VTE, particularly in critically ill/severe patients suffering from COVID-19, was reported as much as $25-27 \%$. A study from three Dutch hospitals showed a $27 \%$ incidence of VTE, including PE and DVT [5]. Another data from China hospital 
revealed 25\% (25/81) patients with severe COVID-19 pneumonia developed lower extremity venous thrombosis [8]. In a study by Xie et al. in Tongji Hospitals, 40\% (10/25) COVID-19 pneumonia confirmed patients who underwent computed tomography pulmonary angiography scans (CTPA) were found to be acute PE positive [9].

\section{Pathomechanism}

COVID-19 may put the patient susceptible to both arterial and venous thromboembolism due to hypoxia, immobilization, disseminated intravascular coagulation (DIC), and excessive inflammation [5]. Systemic pro-inflammatory cytokine responses, including interleukin-1 and interleukin-6, are mediators of atherosclerosis, directly contributing to plaque rupture through local inflammation and hemodynamic changes. These responses also induce procoagulant factors, which predispose to ischemia and thrombosis [4]. Patient with COVID-19 who fell into severe or critical condition is also exposed to other potential risk factors for VTE such as mechanical ventilation, respiratory failure, and use of CVC [5].

Cell entry is an important component for cross-species transmission, particularly for betacoronavirus. Spikes, surface glycoproteins encoded by all coronaviruses which bind to host cell receptors, mediate the entry of viruses. For beta-coronaviruses, the receptor-binding domain, a single region of spike protein, mediates interactions with receptors of host cell. After binding to the receptor, protease of the adjacent host cuts the spike, which liberates fusion peptides in spike, facilitating the entry of the virus. Familiar host receptors for beta-coronavirus include dipeptidyl peptidase-4 for MERS-CoV and angiotensinconverting enzyme 2 (ACE2) for SARS-CoV. In addition, ACE2, which is also the receptor for SARS-CoV-2, is expressed on myocytes and vascular endothelial cells. The dysfunction of vascular endothelial cells is one of the mechanisms of thrombus formation [10].

Endothelial cell dysfunction caused by infection results in excess thrombin production and cessation of fibrinolysis, which indicates a state of hypercoagulability in patients with infections such as COVID-19. In addition, hypoxia found in severe COVID-19 can induce thrombosis by increasing not only viscosity of blood but also signaling pathways that depend on transcription factors induced by hypoxia [11].

Study by Chen et al. revealed index of biochemical examination of 99 patients with COVID-19 pneumonia, and also reported an abnormal biochemical indexes phenomenon related to patients' hemoglobin. This report shows that the number of neutrophils and hemoglobin in most patients decreased, while the rate of erythrocyte sedimentation, serum ferritin, albumin, C-reactive protein, and lactate dehydrogenase in many patients increased significantly [12].
Whenzong and Hualan hypothesize a possible involvement of hemoglobin in the pathogenesis of COVID-19 [13]. When hemoglobin decreases, and heme increases, the body will accumulate too much dangerous iron ions, which will induce inflammation and increase albumin and C-reactive protein. Cells react to stress due to inflammation, creating large amounts of serum ferritin to bind to free iron to reduce destruction [13]. The previous study stated that iron ion might cause endothelial dysfunction, including vascular endothelial. A study by Zhu concludes that intravascular nanoparticles of iron oxide may provoke inflammation and dysfunction of endothelial cells [14]. However, that proposed pathogenesis of hemoglobin in COVID-19 by Whenzong and Hualan has received critical commentary by Read et al. due to the lack of experimental evidence to support any of their conclusions and their claiming the therapeutic effect of drugs that are only just entering clinical trials [15].

The presence of antiphospholipid (aPL) antibodies might also eventually cause thrombosis. Anticardiolipin IgA antibodies, as well as anti$\beta 2$-glycoprotein I IgA and IgG antibodies, were found in COVID-19 patients [6]. Antiphospholipid antibodies target phospholipid protein abnormally, and the presence of these antibodies is important in antiphospholipid syndrome diagnosis. Still, these antibodies can also increase temporarily in patients with critical diseases and various infections. In critical patients such as thrombotic microangiopathy, heparin-induced thrombocytopenia, and disseminated intravascular coagulation, the appearance of these antibodies may rarely cause thrombotic events that are difficult to distinguish from other causes of multifocal thrombosis [6]. The main antigenic target of the aPL antibody is known as $\beta 2$-glycoprotein I ( $\beta 2 \mathrm{GPI})$, mediating the binding of aPL antibodies to target cells, including monocyte, endothelial cells, trophoblast, and platelet, which lead to pro-inflammatory and prothrombotic changes that subsequently result in thrombosis [16].

The net results of those mechanisms may induce the development of subclinical thrombosis in patients suffering from COVID-19. Increased D-dimer, a sign of excessive coagulation activation and hyperfibrinolysis, may explain the result of those pathomechanisms. D-dimer is often used to identify active thrombus with high sensitivity but low specificity. Patients with COVID-19 have an increase of the D-dimer level. After undergoing therapeutic anticoagulation, D-dimer level decreases continuously, which means D-dimer can predict not only thrombosis but also monitor anticoagulant's effectiveness [7]. Another evidence, histopathology study on lung biopsy of critical patients with COVID-19, revealed the presence of occlusion and microthrombosis formation in pulmonary small vessels [17]. 


\section{Risk assessment and diagnosis}

It is important to identify which patients with COVID-19 are at increased risk of VTE. Current clinical recommendation state that thromboprophylaxis should be given to all acute patient with high risk of VTE. Modified IMPROVE-VTE risk score is a scoring system that combines D-Dimer level with other VTE clinical predictors to identify patients with high-risk VTE who are eligible for thromboprophylaxis medication (Table 1). Marker for higher VTE risk is a total score of 4 or 2-3 with $\mathrm{D}$-dimer level at the time of screening is more than twice the upper limit of normal range [18]

\section{Table 1: Modified IMPROVE VTE risk score}

\begin{tabular}{|c|c|}
\hline VTE risk factor & VTE risk score \\
\hline Previous VTE & 3 \\
\hline Known thrombophilia ${ }^{a}$ & 2 \\
\hline Current lower limb paralysis or paresis ${ }^{\mathrm{b}}$ & 2 \\
\hline History of cancer ${ }^{\circ}$ & 2 \\
\hline ICU/CCU stay & 1 \\
\hline Complete immobilization $^{d} \geq 1$ day & 1 \\
\hline Age $\geq 60$ years & 1 \\
\hline \multicolumn{2}{|c|}{$\begin{array}{l}\text { CCU: Cardiac care unit, ICU: Intensive care unit, IMPROVE: International Medical Prevention Registry } \\
\text { on Venous Thromboembolism, NIH: National Institutes of Health, VTE: Venous thromboembolism. }{ }^{\mathrm{a}} \mathrm{A} \\
\text { congenital or acquired condition that causes the risk of excessive thrombosis (e.g., factor } \mathrm{C} \text { or } \mathrm{S} \text { deficiency, } \\
\text { lupus anticoagulant, Leiden Factor V). }{ }^{b} \text { Feet falls into bed } 5 \mathrm{~s} \text { but has an effort against gravity (taken from } \\
\text { the NIH stroke scale). }{ }^{\circ} \text { Cancer (not including non-melanoma skin cancer) at any time in the past } 5 \text { years } \\
\text { (cancer must be in remission to meet eligibility criteria). }{ }^{\circ} \text { Immobilization is limited to beds or chairs with or } \\
\text { without bathroom privileges. }\end{array}$} \\
\hline
\end{tabular}

\section{Risk of pulmonary embolism}

The clinical manifestation of acute PE is not specific. Symptoms include chest pain, dyspnea, hemoptysis, and syncope. COVID-19 may exhibit symptoms that bear a misleading resemblance to acute PE. This generates a diagnostic challenge for clinician treating patient with COVID-19. Identifying the presence of risk factors of VTE is vital to determine disease clinical probability. Revised Geneva Rule and Wells Score are often used as prediction rules. They combine symptoms, clinical findings, and risk factors to classify patients with suspected PE into specific category, separating them from the others. Acute thrombosis will activate coagulation and fibrinolysis, leading to increase serum D-dimer. D-dimer has high negative predictive value in diagnosing acute PE. If D-dimer level is normal, then the diagnosis of acute $\mathrm{PE}$ is unlikely. Meanwhile, the positive predictive value of high D-dimer is low. Making it less meaningful to confirm the presence of acute PE [19].

Several studies reported that increased D-dimer levels (>1000 $\mathrm{ng} / \mathrm{mL}$ ) are a potential predictor for mortality. D-dimer level has low specificity value, making it unfavorable as a screening tool. Relying D-Dimer as screening tool might cause overutilization of CTPA if applied in patients with acute kidney injury [20].

Prompt diagnosis of PE for patient presenting with respiratory distress, desaturation, and hypotension is crucial to improve the clinical outcomes. Despite the lack of evidence, assessment of serial D-dimer alongside imaging modalities such as bedside echocardiography or Doppler ultrasound will provide valuable information to determine the presence of $\mathrm{PE}$ in patients with COVID-19 infection [21]. A recent study examining 25 patients suspected of PE showed that $D$-dimer levels in patients with confirmed PE had values higher than $7000 \mathrm{ng} / \mathrm{mL}$, significantly higher than those without PE [9], [21].

\section{Risk of deep vein thrombosis}

The initial step in the diagnostic algorithm of DVT suspicion is using two levels modified wells score. It will classify DVT suspected patients into two categories (DVT unlikely or likely). For DVT-unlikely, D-dimer examination is established. Normal D-dimer renders DVT unlikely. In patients with DVT-likely, D-Dimer testing is not required, but imaging is required. If not contraindicated, anticoagulation therapy must be started in patients with DVT-likely until imaging. First-line imaging modality of DVT is venous ultrasonography [22].

\section{Elevated serum D-dimer level}

Study by Cui, et al. revealed that one-fourth of COVID-19 patients developed VTE. VTE was strongly correlated with elevated serum D-dimer level, as shown in Table 2. The authors subsequently tested several D-dimer cutoff value to predict VTE occurrence (Table 3). The best cutoff of D-Dimer value was $1500 \mathrm{ng} /$ $\mathrm{ml}(85 \%$ sensitivity and $89 \%$ specificity). This supports the concept of empiric anticoagulation for patients with markedly elevated D-dimers (particularly in situations where frequent CT angiography and Doppler Ultrasound is impossible due to logistic restraints) [8].

Table 2: Characteristics between the VTE and non-VTE groups $(n=81)$

\begin{tabular}{lllll}
\hline Characteristics & Normal range & VTE $(n=20)$ & Non-VTE $(n=61)$ & p-value \\
\hline Age (years) & - & $68.4 \pm 9.1$ & $57.1 \pm 14.3$ & 0.001 \\
Leukocytes $(\times 109 / \mathrm{L})$ & $3.5-9.5$ & $7.8 \pm 3.1$ & $6.6 \pm 2.6$ & 0.120 \\
Lymphocytes $(\times 109 / \mathrm{L})$ & $1.1-3.2$ & $0.8 \pm 0.4$ & $1.3 \pm 0.6$ & $<0.001$ \\
Platelets $(\times 109 / \mathrm{L})$ & $125.0-350.0$ & $246.6 \pm 110.6$ & $248.8 \pm 111.7$ & 0.938 \\
Hemoglobin $(\mathrm{g} / \mathrm{L})$ & $115.0-150.0$ & $123.2 \pm 16.5$ & $125.3 \pm 16.7$ & 0.633 \\
APTT $(\mathrm{s})$ & $27.0-45.0$ & $39.9 \pm 6.4$ & $35.6 \pm 4.5$ & 0.001 \\
Prothrombin time $(\mathrm{s})$ & $11.0-16.0$ & $15.4 \pm 1.0$ & $15.6 \pm 1.0$ & 0.465 \\
D-dimer $(\mathrm{ug} / \mathrm{mL})$ & $0.0-0.5$ & $5.2 \pm 3.0$ & $0.8 \pm 1.2$ & $<0.001$ \\
\hline
\end{tabular}

Due to current limited studies, initiating full dose of anticoagulation based on D-dimer value will remain controversial. For now, these decisions may be judged on a patient-by-patient basis, considering both risks of thrombosis and hemorrhage. Among patients without risk factors for hemorrhage, empiric anticoagulation may be reasonable for patients with D-dimer levels above $\sim 1500 \mathrm{ng} / \mathrm{ml}$ [8].

Table 3: Sensitivity, specificity, positive predictive value, and negative predictive value of different D-dimer cutoff levels for predicting VTE in COVID-19 patients

\begin{tabular}{lllll}
\hline Cutoff $(\mu \mathrm{g} / \mathrm{mL})$ & Sensitivity $(\%)$ & Specificity $(\%)$ & PPV $(\%)$ & NPV $(\%)$ \\
\hline 1.0 & 85.0 & 77.0 & 54.8 & 94.0 \\
1.5 & 85.0 & 88.5 & 70.8 & 94.7 \\
2.0 & 80.0 & 90.2 & 72.7 & 93.2 \\
2.5 & 70.0 & 93.4 & 77.8 & 90.5 \\
3.0 & 70.0 & 96.7 & 87.5 & 90.8 \\
3.5 & 65.0 & 96.7 & 86.7 & 89.4 \\
\hline PPV: Positive predictive value, NPV: Negative predictive value & &
\end{tabular}


In conclusion, modified IMPROVE-VTE risk score and serum D-Dimer level are valuable tools to help identify COVID-19 patients at increased risk of VTE. Increased D-Dimer level above $1500 \mathrm{ng} / \mathrm{ml}$ has the best sensitivity and specificity value for predicting the VTE events in COVID-19 patients. The diagnosis of PE and DVT require imaging modality such as bedside echocardiography or Doppler ultrasound.

\section{Management}

\section{Anticoagulant}

Most patients with COVID-19 may have excessive activation of coagulation and will consequently have microthrombi [17]. Hence, several interim guidelines and health-care center protocols agreed that all hospitalized COVID-19 patients must all be in some form of anticoagulation, whether it is confirmed VTE or not [23], [24], [25], [26], [27].

Heparin, including LMWH or its synthetic form, is commonly used as an anticoagulant to prevent DIC and VTE in patients with infection due to its anti-inflammatory effects. As well as preventing thrombosis, heparin has its property to lower cytokine levels and prevents cytokine storm in patients with COVID-19 [23], [28], [29]. American Society of Hematology (ASH) recommends LMWH or Fondaparinux over UFH for all hospitalized patients unless increased bleeding risk is present. While in patients with heparin-induced thrombocytopenia history, it is recommended to use fondaparinux. If anticoagulants are not available or contraindicated, then mechanical thromboprophylaxis is advised (e.g., pneumatic compression device) [24], [30].

A retrospective analysis by Tang etal. comparing 28-day mortality between heparin users and non-users of 449 consecutive patients with severe COVID-19 was done in China. Ninety-nine patients had received heparin for 7 days or longer. They found no significant difference in 28-day mortality between heparin users and non-users ( $30.3 \%$ vs. $29.7 \%$ p $=0.910)$. However, in patients with sepsis-induced coagulopathy (SIC) score $\geq 4$ (Table 4 ), mortality was significantly reduced by anticoagulant medication $(p=0.029)$. In patients with D-dimers $>3000 \mathrm{ng} / \mathrm{mL}$ ( 6 times of the normal upper limit), anticoagulation results in a $20 \%$ mortality reduction $(p=0.017)$ [11].

Table 4: ISTH SIC scoring system [11]

\begin{tabular}{lll}
\hline Item & Score & Range \\
\hline Platelet count $(\times 109 / \mathrm{L})$ & 1 & $100-150$ \\
PT-INR & 2 & $<100$ \\
& 1 & $1.2-1.4$ \\
SOFA score & 2 & $>1.4$ \\
& 1 & 1 \\
Total score for SIC & 2 & $\geq 2$ \\
\hline INR: International normalized ratio, ISTH: The International Society on Thrombosis and Hemostasis,
\end{tabular}

SIC: Sepsis-induced coagulopathy, SOFA: Sequential organ failure assessment
The International Society of Thrombosis and Hemostasis (ISTH)

The interim guidance delivers risk stratification of coagulopathy at admission for patients with COVID-19 and coagulopathy management (Figure 1) [23]. Their recommendations including:

1. Patients with high D-dimers (e.g., arbitrarily defined as 3-4 times increase) will need to be hospitalized.

2. Monitoring the reduction in fibrinogen levels later in the course of the disease (e.g., days 10-14) can help in determining whether the patient has progressed to DIC.

3. LMWH should be considered in all patients (including those who are not critical) who need to be hospitalized for COVID-19, if there are no contraindications:

- $\quad$ Active hemorrhage

- $\quad$ Platelet count $<25 \times 10^{9} / \mathrm{L}$

- Monitoring recommended for severe renal impairment

- AbnormalPToraPTT is nota contraindication

4. LMWH might carry anti-inflammatory properties that provide added benefits in COVID-19 infection.

\section{Prophylactic anticoagulant}

Brigham and Women's Hospital guideline recommendation of standard prophylactic anticoagulation for thrombotic disease management in all hospitalized COVID-19 is as follows [27]:

1. If $\mathrm{GFR}>30 \mathrm{~mL} / \mathrm{min}$ : Enoxaparin $40 \mathrm{mg}$ subcutaneous (SC) daily

2. If $\mathrm{GFR}<30 \mathrm{~mL} / \mathrm{min}$ or acute kidney injury: Unfractionated heparin (UFH) 5000 units SC q8hr

3. Hold if platelets $<30,000$ or bleeding, start thromboembolic deterrent stockings, and sequential compression devices.

Klok et al. reported that in spite of prophylaxis anticoagulant administration, $27 \%$ of patients had later developed VTE, and $4 \%$ had an incidence of arterial thromboembolism (which may be underestimated, due to the lack of systematic screening for this event and the interrupted observation period in some patients). As a result, they recommend doubling the conventional dose of heparin prophylaxis (e.g., Enoxaparin $40 \mathrm{mg}$ twice a day, rather than once a day) [5]. Prophylactic doses higher than standard doses can also be considered in patients with elevated D-dimers (e.g., 500-1500 ng/mL) [31]:

GFR > $30 \mathrm{~mL} / \mathrm{min}$ : Enoxaparin $0.5 \mathrm{mg} / \mathrm{kg}$ q12hr. Check anti-Xa level $4 \mathrm{~h}$ after the third dose, with a target level of $0.5-0.8 \mathrm{IU} / \mathrm{ml}$.

1. GFR < $30 \mathrm{~mL} / \mathrm{min}:$ UFH 7500 units $\mathrm{q} 8 \mathrm{hr}$ (consider dose adjustment for atypical weight patients). 


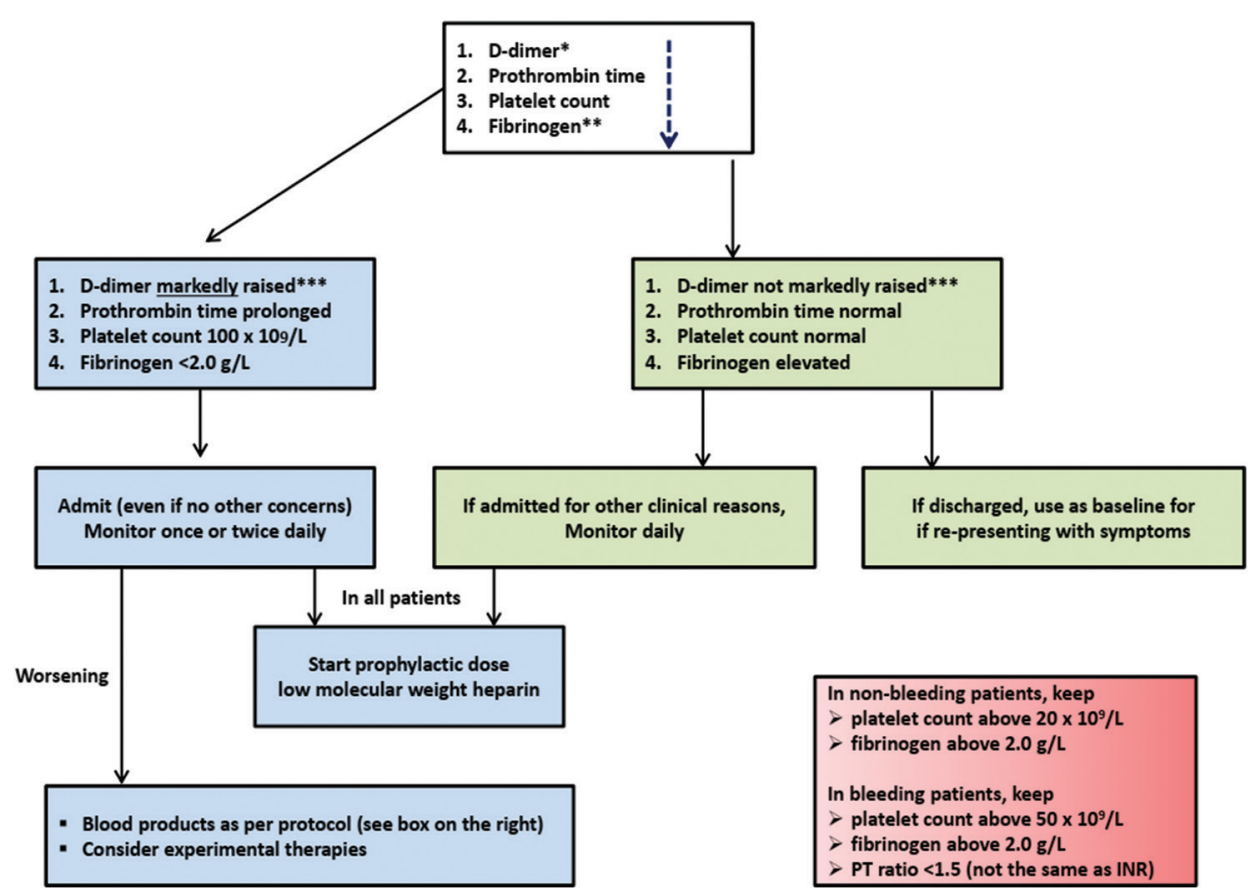

Figure 1: Algorithm of coagulopathy management in COVID-19 build on simple laboratory parameters. *The list of parameters is written in descending order of importance. ${ }^{* *}$ Taking a fibrinogen test may not be available in some laboratories, but monitoring levels can be helpful after hospitalization. ${ }^{* * *}$ Even though the specific cutoff cannot be defined, an increase in D-dimer 3-4-fold can be considered significant. One of the values in this table can be considered significant [23]

\section{Therapeutic anticoagulant}

Therapeutic anticoagulation with heparin has been proposed for patients with D-dimers level greater than $2000 \mathrm{ng} / \mathrm{ml}$, but this has not been proven [11], [32]. At present, therapeutic anticoagulation was limited to COVID-19 patients with documented acute VTE, and prehospital management with therapeutic anticoagulation (such as for recurrentVTE, certain mechanical heart valves, and atrial fibrillation). In general, the recommendation for VTE therapeutic as follows [23], [25], [26, [27], [33]:

1. If the patient uses direct oral anticoagulant (DOAC) or warfarin for Afib or VTE, switch to the full dose of anticoagulant (LMWH or UFH, according to indications based on kidney function or clinical conditions; LMWH is preferred over UFH to reduce blood drawing in monitoring PTT because of more possible interactions with COVID 19).

2. If the patient has confirmed acute PE or DVT or is undergoing anticoagulant therapy before being hospitalized and is now converted to parenteral, the following guidelines are recommended:

a. LMWH is preferred to minimize blood drawing and has superior efficacy in critical care population [26].

b. Patients who need to use UFH (not LMWH) should be monitored with anti-Xa levels (in contrast to PTT given that the increases in COVID-19 patients who are severe and can make PTT unreliable) [26].

3. Consult with a hematologist to discuss specific guidelines if coagulopathy in the patient appears to be deteriorating or to discuss an escalated or modified treatment approach, as some hematologic disorder such as thrombocytopenia increased risk of severity and mortality in COVID-19 [34].

4. Farkas proposed a possible approach to empiric anticoagulation with a limit of D-dimer above 1000-2000 ng/ml, fibrinogen level, thromboelastography (TEG) as guidance, as shown in Figure 2. This author states that this approach has not yet been supported by any high-level evidence, and the decision to provide anticoagulants should preferably be individualized, so this is only intended as an approach scheme in the management of patients. In the case of very advanced stages, severe disease may be characterized by low fibrinogen levels, which can produce hemorrhagic clinics, where anticoagulation can theoretically be dangerous in that condition [31].

Yale-New Haven Hospital (YNHH) and Massachusetts General Hospital (MGH) issued a local protocol of anticoagulation dosing guidelines including LMWH, heparin, fondaparinux, and DOAC (apixaban, rivaroxaban, and dabigatran) in prophylaxis and therapeutic management of VTE, as shown in Table 5.

\section{Direct oral anticoagulant (DOAC)}

Because of possible drug interactions between DOAC and combinations of antiviral (especially 


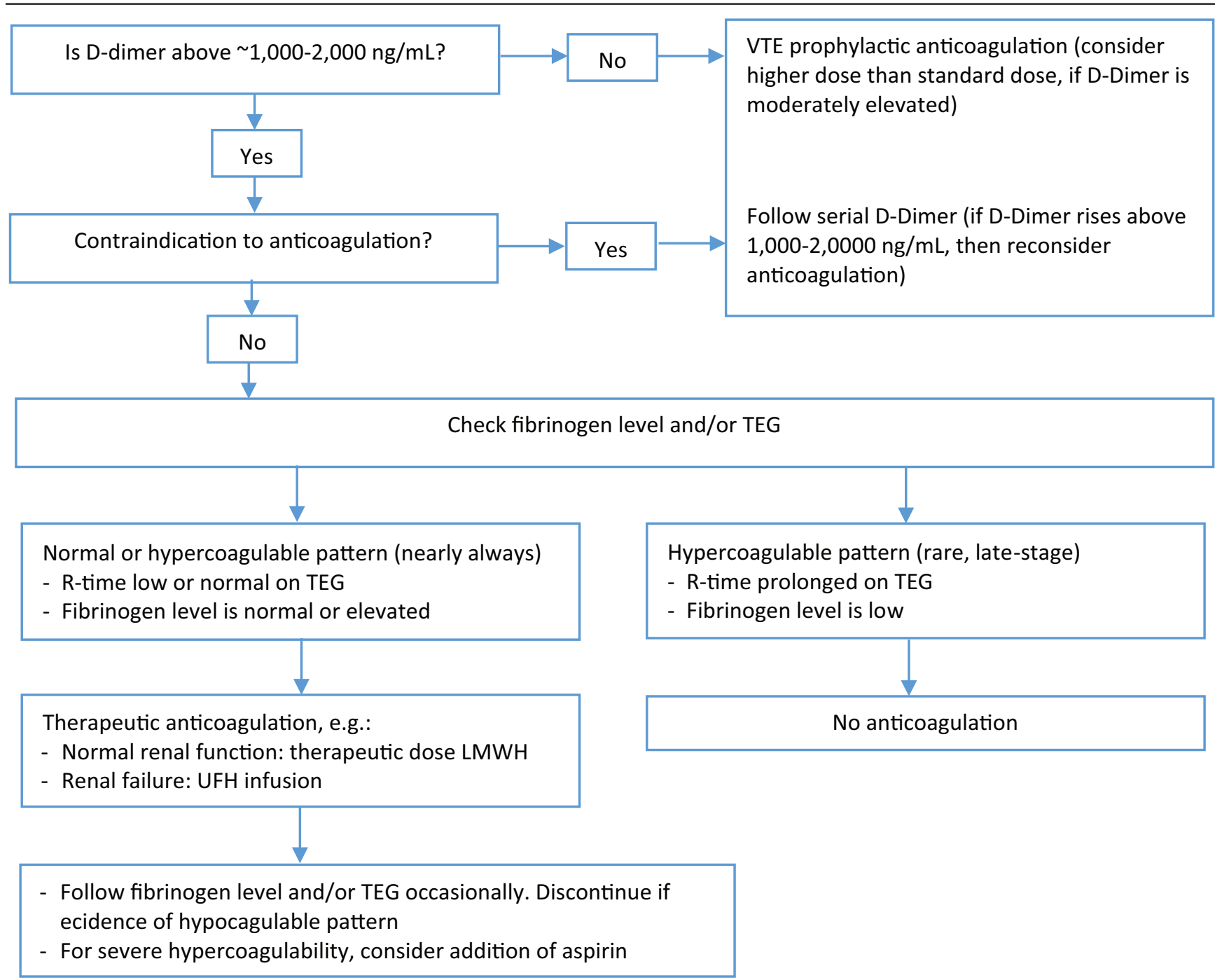

Figure 2: Possible approach to empiric anticoagulation in COVID-19 (adapted from Farkas, 2020) [31]. LMWH: Low molecular weight heparin, TEG: Thromboelastography, UFH: Unfractionated heparin.

anti-HIV protease inhibitors such as ritonavir) and antibacterial (such as azithromycin), LMWH or UFH should be preferred over DOAC. Such antiviral and antibacterial therapy interferes with the CYP3A4 and/or P-GP pathways, which can increase the risk of bleeding or reduce the antithrombotic effect in the case of DOAC use [19].

\section{Fibrinolytic}

At present, there are not enough data suggesting the use of more advanced therapies such as tissue plasminogen activator/tPA or to increase the dose of prophylactic anticoagulation in VTE associated with critically ill COVID-19 patients. There is evidence in animals and humans that fibrinolytic in acute lung injury and acute respiratory distress syndrome (ARDS) improves survival. This evidence also shows fibrin deposition in pulmonary microvasculature as the main cause of ARDS and is expected to be found in ARDS patients and a concurrent diagnosis of DIC seen in laboratory parameters, as observed in more than $70 \%$ of patients who died from COVID-19 [35]. Wang et al. reported three cases of intravenous tPA off-label (Alteplase) in COVID-19 patients with ARDS and respiratory failure. In all cases, patients showed an initial increase in the P/F ratio. However, the observed increase was temporary and disappeared over time in all three patients after completing their tPA infusion. They also mentioned that larger bolus tPA doses (50 mg or $100 \mathrm{mg}$ bolus) without retaining anticoagulants are worth further considering and research to prevent the recurrence of suspected thrombosis of pulmonary microvascular that underlies ARDS in COVID-19 [35].

In conclusion, it is reasonable to give anticoagulant for prophylaxis treatment to all admitted patient with COVID-19. Heparin is the preferred anticoagulant for patients with COVID-19 because of its anti-inflammation property. Therapeutic anticoagulant should be given to patient with confirmed VTE or has high suspicion of developing VTE. The decision to give anticoagulation should be judged on patient-bypatient basis, considering both risks of thrombosis and hemorrhage. 
Table 5: Prophylactic and therapeutic dosing of anticoagulation in VTE management

\begin{tabular}{|c|c|c|c|}
\hline D-dimer & Brigham and Women's Hospital (BWH) & Yale-New Haven Hospital (YNHH) & Massachusetts General Hospital (MGH) \\
\hline$<500 \mathrm{ng} / \mathrm{mL}:$ & GFR $>30 \mathrm{ml} / \mathrm{min}:$ & $\mathrm{BMI}<40 \mathrm{~kg} / \mathrm{m}^{2}$ & Standard dose \\
\hline \multirow[t]{12}{*}{ Prophylactic dose } & Enoxaparin 40 mg SC q24h & GFR $\geq 30:$ & UFH: 5000 units SC q12h \\
\hline & GFR $<30 \mathrm{ml} / \mathrm{min}:$ & Enoxaparin $40 \mathrm{mg} \mathrm{SC}$ q24h & Enoxaparin: 40 mg SC q24h \\
\hline & UFH 5000 units SC q8h & GFR $<30$ : & Fondaparinux: $2.5 \mathrm{mg} \mathrm{SC}$ q24h \\
\hline & & Enoxaparin 30 mg SC q24h & Apixaban: 2.5 mg PO q12h \\
\hline & & UFH 5000 units SC q12h & Rivaroxaban: 10 mg PO q24h \\
\hline & & $\mathrm{BMI} \geq 40 \mathrm{~kg} / \mathrm{m}^{2}$ & Dabigatran: $110 \mathrm{mg}$ followed by $220 \mathrm{mg}$ \\
\hline & & GFR $\geq 30:$ & q24h \\
\hline & & Enoxaparin 40 mg SC q12h & $\mathrm{BMI} \geq 40 \mathrm{~kg} / \mathrm{m}^{2}$ \\
\hline & & GFR $<30$ : & UFH: 5000 units SC q8h \\
\hline & & Enoxaparin 40 mg SC q24h & Enoxaparin: \\
\hline & & Heparin 7500 units SC q12h & GFR $\geq 30: 40 \mathrm{mg} \mathrm{SC} \mathrm{q12h}$ \\
\hline & & & GFR < 30: 40 mg SC q24h \\
\hline \multirow{17}{*}{$\begin{array}{l}\geq 500 \mathrm{ng} / \mathrm{mL}: \\
\text { Intermediate } \\
\text { prophylactic dose }\end{array}$} & Recommended higher prophylactic & $\mathrm{BMI}<40 \mathrm{~kg} / \mathrm{m}^{2}$ & $\mathrm{n} / \mathrm{a}$ \\
\hline & dose by Klok et al. and Farkas. & GFR $\geq 30$ : & \\
\hline & GFR > $30 \mathrm{ml} / \mathrm{min}:$ & Enoxaparin 0,5 mg/kg SC q12h & \\
\hline & Enoxaparin $0.5 \mathrm{mg} / \mathrm{kg}$ q12h. Check an Xa level & Apixaban & \\
\hline & four hours after the third dose, targeting a level & GFR < 30: & \\
\hline & of $\sim 0.5-0.8 \mathrm{IU} / \mathrm{ml}$ & Enoxaparin 0,5 mg/kg SC q12h & \\
\hline & GFR $<30 \mathrm{ml} / \mathrm{min}:$ & Apixaban & \\
\hline & UFH 7,500 units q8hr (consider dose adjustment & UFH 7500 units SC q12h & \\
\hline & for atypical weight patients). & $\mathrm{BMI} \geq 40 \mathrm{~kg} / \mathrm{m}^{2}$ & \\
\hline & & GFR $\geq 30:$ & \\
\hline & & Enoxaparin 0,5 mg/kg SC q12h & \\
\hline & & Apixaban & \\
\hline & & GFR < 30: & \\
\hline & & Enoxaparin 0,5 mg/kg SC q12h & \\
\hline & & Apixaban & \\
\hline & & UFH 7500 units SC q12h & \\
\hline & & 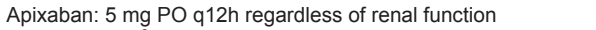 & \\
\hline \multirow{17}{*}{$\begin{array}{l}\text { Confirmed VTE } \\
\text { or high clinical } \\
\text { suspicion: } \\
\text { Therapeutic dose }\end{array}$} & $\mathrm{n} / \mathrm{a}$ & $\mathrm{BMI}<40 \mathrm{~kg} / \mathrm{m}^{2}$ & Standard dose: \\
\hline & & GFR $\geq 30:$ & UFH: 80 unit $/ \mathrm{kg}$ bolus +18 units $/ \mathrm{kg} / \mathrm{hr}$ \\
\hline & & Enoxaparin 0,5 mg/kg SC q12h & infusion \\
\hline & & Apixaban & Enoxaparin: 1 mg/kg SC q12h \\
\hline & & GFR < 30: & Fondaparinux: \\
\hline & & Enoxaparin 0,5 mg/kg SC q12h & $<50 \mathrm{~kg}: 5 \mathrm{mg} \mathrm{SC}$ q24h \\
\hline & & Apixaban & $50-100 \mathrm{~kg}: 7.5 \mathrm{mg} 124 \mathrm{~h}$ \\
\hline & & Therapeutic UFH & $>100 \mathrm{~kg}: 10 \mathrm{mg} \mathrm{q} 24 \mathrm{~h}$ \\
\hline & & $\mathrm{BMI} \geq 40 \mathrm{~kg} / \mathrm{m}^{2}$ & $\mathrm{BMI} \geq 40 \mathrm{~kg} / \mathrm{m}^{2}$ \\
\hline & & GFR $\geq 30$ : & Enoxaparin: \\
\hline & & Enoxaparin $0,5 \mathrm{mg} / \mathrm{kg} \mathrm{SC}$ q12h & $\mathrm{GFR} \geq 30: 0.75 \mathrm{mg} / \mathrm{kg} \mathrm{q} 12 \mathrm{~h}$ \\
\hline & & Apixaban & GFR < 30: $0.75 \mathrm{mg} / \mathrm{kg}$ q24h \\
\hline & & GFR $<30:$ & \\
\hline & & Enoxaparin 1 mg/kg SC q24h & \\
\hline & & Apixaban & \\
\hline & & Therapeutic UFH & \\
\hline & & Apixaban: $10 \mathrm{mg}$ PO q12h $\times 7$ days followed by $5 \mathrm{mg} P O \mathrm{q} 12 \mathrm{~h}$ & \\
\hline
\end{tabular}

\section{Prognosis}

Several studies proved the role of increased D-dimers as a predictor of mortality. Higher levels of D-dimer and fibrin degradation products showed to have associated with multi-organ dysfunction syndrome and worse prognosis [4], [7]. Huang et al. showed that the level of D-dimer at admission was higher in patients who needed critical care support (median [range] D-dimer level $2400 \mathrm{ng} / \mathrm{mL}$ [600-14.400]) compared to patients who did not need it (median [range] ] D-dimer level $0.5 \mathrm{ng} / \mathrm{mL}$ [300-800], $\mathrm{p}=0.0042$ ) [29]. Tang et al. reported DIC development on the $4^{\text {th }}$ day in $71.4 \%$ of patients who did not survive compared to only one patient $(0.6 \%)$ who survived. They also reported increased D-dimer and PT levels with decreased levels of fibrinogen in those who did not survive on $10^{\text {th }}$ and $14^{\text {th }}$ days significantly [7].

Sepsis patients are more likely to develop multi-organ failure in the presence of coagulopathy. Giving these patients medication which inhibits thrombin formation will likely aid in reducing mortality [23]. Study by Tang et al. proposed that monitoring D-dimers, PT, fibrinogen, and platelet counts can help to determine prognosis in patients with COVID-19. Aggressive critical care support is proposed if these parameters worsen.

Thrombocytopenia at presentation is considered to be a prognostic factor for mortality (OR, 5.1; 95\% Cl, 1.8-14.6), as stated by Lippi et al. [34]. Thus, this study suggests the clinician provide adequate blood product and consider giving more "experimental' therapies" as the data regarding therapies in COVID-19 are still limited [7], [23].

\section{Conclusion}

Patients suffering from COVID-19 are at high risk of developing thrombosis, including VTE. Excessive inflammation, hypoxia, immobilization, aPL antibody, and diffuse intravascular coagulation contributes to development of VTE. There has been upcoming evidence regarding the presence of thrombosis in patients with severe COVID-19 infection. Prophylaxis anticoagulant 
was proposed for all hospitalized COVID-19 patients. However, until additional data are available, when to initiate full therapeutic anticoagulation will remain controversial. For now, these decisions may be judged on a patient-by-patient basis, considering both risks of thrombosis and hemorrhage. Anti-inflammatory effect of LMWH may provide additional benefit in COVID-19 patients.

\section{Acknowledgment}

This article is supported by Vascular Division Department of Cardiology and Vascular Medicine, Dr. Soetomo General Hospital, Surabaya, Indonesia.

\section{References}

1. World Health Organization. Coronavirus Disease (COVID-19) Pandemic; 2020. Available from: https://www.who.int/ emergencies/diseases/novel-coronavirus-2019. [Last accessed on 2020 Apr 21].

2. Susilo A, Rumende CM, Pitoyo CW, Santoso WD, Yulianti M, Sinto R, et al. Coronavirus disease 2019: Review of current literatures. J Penyakit Dalam Indones. 2020;7(1):45-67. https:// doi.org/10.7454/jpdi.v7i1.415

3. Yang X, Yu Y, Xu J, Shu H, Xia J, Liu H, et al. Clinical course and outcomes of critically ill patients with SARS-CoV-2 pneumonia in Wuhan, China: A single-centered, retrospective, observational study. Lancet Respir Med. 2020;2600(20):1-7. https://doi. org/10.1016/s2213-2600(20)30079-5

4. Zhou F, Yu T, Du R, Fan G, Liu Y, Liu Z, et al. Clinical course and risk factors for mortality of adult inpatients with COVID-19 in Wuhan, China: A retrospective cohort study. Lancet. 2020;395(10229):1054-62. https://doi.org/10.1016/ s0140-6736(20)30566-3

PMid:32171076

5. Klok FA, Kruip MJ, van der Meer NJ, Arbous MS, Gommers DA, Kant KM, et al. Incidence of thrombotic complications in critically ill ICU patients with COVID-19. Thromb Res. 2020;191:145-7. https://doi.org/10.1016/j.thromres.2020.04.041

PMid:32291094

6. Zhang $\mathrm{Y}$, Xiao $\mathrm{M}$, Zhang $\mathrm{S}$, Xia $\mathrm{P}$, Cao W, Jiang $\mathrm{W}$, et al. Coagulopathy and antiphospholipid antibodies in patients with covid19. N Engl J Med. 2020;382(17):e38.

PMid:32268022

7. Tang N, Li D, Wang X, Sun Z. Abnormal coagulation parameters are associated with poor prognosis in patients with novel coronavirus pneumonia. J Thromb Haemost. 2020;18(5):844-7. https://doi.org/10.1111/jth. 14768

PMid:32291954

8. Cui S, Chen S, Li X, Liu S, Wang F. Prevalence of venous thromboembolism in patients with severe novel coronavirus pneumonia. J Thromb Haemost. 2020;18(6):1421-4. https://doi. org/10.1111/jth. 14830

PMid:32271988

9. Chen J, Wang X, Zhang S, Liu B, Wu X, Wang Y, et al. Findings of acute pulmonary embolism in COVID-19 patients. Lancet Infect Dis. 2020. https://doi.org/10.2139/ssrn.3548771.

10. Xu J, Fan J, Wu F, Huang Q, Guo M, Lv Z, et al. The ACE2/ angiotensin-(1-7)/Mas receptor axis: Pleiotropic roles in cancer. Front Physiol. 2017;8:276. https://doi.org/10.3389/ fphys.2017.00276

PMid:28533754

11. Tang N, Bai H, Chen X, Gong J, Li D, Sun Z. Anticoagulant treatment is associated with decreased mortality in severe coronavirus disease 2019 patients with coagulopathy. J Thromb Haemost. 2020;18(5):1094-9. https://doi.org/10.1111/jth.14817 PMid:32220112

12. Chen N, Zhou M, Dong $\mathrm{X}, \mathrm{Qu} \mathrm{J}$, Gong $\mathrm{F}$, Han $\mathrm{Y}$, et al Epidemiological and clinical characteristics of 99 cases of 2019 novel coronavirus pneumonia in Wuhan, China: A descriptive study. Lancet. 2020;395(10223):507-13. https://doi.org/10.1016/ s0140-6736(20)30211-7

13. Wenzhong L, Hualan L. COVID-19: ATTACKS the 1-Beta Chain of Hemoglobin and Captures the Porphyrin to Inhibit Human Heme Metabolism. ChemRxiv; 2020. Available from: https://www.chemrxiv.org/articles/COVID-19_disease_ORF8_ and_surface_glycoprotein_inhibit_heme_metabolism_by_ binding_to_porphyrin/11938173. chemrxiv.11938173.v4

14. Zhu MT, Wang B, Wang Y, Yuan L, Wang HJ, Wang M, et al. Endothelial dysfunction and inflammation induced by iron oxide nanoparticle exposure: Risk factors for early atherosclerosis. Toxicol Lett. 2011;203(2):162-71. https://doi.org/10.1016/j. toxlet.2011.03.021

PMid:21439359

15. Read R. Flawed methods in "COVID-19: Attacks the 1-Beta Chain of Hemoglobin and Captures the Porphyrin to Inhibit Human Heme Metabolism. ChemRxiv; 2020. Available from: https:// www.chemrxiv.org/articles/Flawed methods in COVID-19 Attacks_the_1-beta_chain_of_hemoglobin_and_captures_the porphyrin_to_inhibit_human_heme_metabolism_/12120912. https://doi.org/10.26434/chemrxiv.12120912

16. Harper BE, Willis R, Pierangeli SS. Pathophysiological mechanisms in antiphospholipid syndrome. Int J Clin Rheumtol. 2011;6(2):157-71.

PMid:23487578

17. Luo W, Yu H, Gou J, Li X, Sun Y, Li J, et al. Clinical pathology of critical patient with novel coronavirus pneumonia (COVID 19). Preprints. 2020;2020:1-15. Available from: https://www. preprints.org/manuscript/202002.0407/v1.

18. Spyropoulos AC, Lipardi C, Xu J, Peluso C, Spiro TE, De Sanctis Y, et al. Modified IMPROVE VTE risk score and elevated D-dimer identify a high venous thromboembolism risk in acutely III medical population for extended thromboprophylaxis. TH Open. 2020;4(1):e59-65. https://doi.org/10.1055/s-0040-1705137 PMid:32190813

19. Konstantinides SV, Meyer G, Bueno H, Galié N, Gibbs JS, Ageno W, et al. ESC guidelines for the diagnosis and management of acute pulmonary embolism developed in collaboration with the European respiratory society (ERS). Eur Heart J. 2020;41(4):543-603. https://doi.org/10.1016/j. rec.2020.05.013

PMid:31504429

20. Casey K, Iteen A, Nicolini R, Auten J. COVID-19 pneumonia with hemoptysis: Acute segmental pulmonary emboli associated with novel coronavirus infection. Am J Emerg Med. 2020;2020:30239. https://doi.org/10.1016/j.ajem.2020.04.011 PMid:32312574

21. Terpos E, Ntanasis-Stathopoulos I, Elalamy I, Kastritis E, Sergentanis TN, Politou M, et al. Hematological findings and complications of COVID-19. Am J Hematol. 2020;2020:25829. 
https://doi.org/10.1002/ajh.25829

PMid:32282949

22. Mazzolai L, Aboyans V, Ageno W, Agnelli G, Alatri A, Bauersachs $\mathrm{R}$, et al. Diagnosis and management of acute deep vein thrombosis: $A$ joint consensus document from the European society of cardiology working groups of aorta and peripheral vascular diseases and pulmonary circulation and right ventricular function. Eur Heart J. 2018;39(47):4208-18. https://doi.org/10.1093/eurheartj/ehx003

PMid:28329262

23. Thachil J, Tang N, Gando S, Falanga A, Cattaneo M, Levi M, et al. ISTH interim guidance on recognition and management of coagulopathy in COVID-19. J Thromb Haemost. 2020;2020:14860. https://doi.org/10.1111/jth.14810 PMid:32302462

24. Schünemann HJ, Cushman M, Burnett AE, Kahn SR, BeyerWestendorf J, Spencer FA, et al. American Society of Hematology 2018 guidelines for management of venous thromboembolism: prophylaxis for hospitalized and nonhospitalized medical patients. Blood Adv. 2018;2(22):3198-225. https://doi. org/10.1182/bloodadvances.2018022954 PMid:30482763

25. Yale New Haven Health System. YNHHS Initial Treatment Algorithm for Hospitalized ADULTS with COVID-19. New Haven, Connecticu: Yale New Haven Health System; 2020. Available from: https://www.medicine.yale.edu/intmed/COVID19TREATMENT ADULT Algorithm 04142020_382832_5 v3.pdf. [Last accessed on 2020 Apr 17].

26. MGH. Massachusetts General Hospital-Hematology Issues during COVID-19; 2020. Available from: https://www.massgeneral.org/ assets/MGH/pdf/news/coronavirus/guidance-from-mass-generalhematology.pdf. [Last accessed on 2020 Apr 17].

27. BWH. Hematology COVID-19 Protocols; 2020. Available from: https://www.covidprotocols.org/protocols/09-hematology \#thrombotic-disease. [Last accessed on 2020 Apr 17].

28. Shi C, Wang C, Wang H, Yang C, Cai F, Zeng F, et al. Clinical Observations of Low Molecular Weight Heparin in Relieving Inflammation in COVID-19 Patients: A Retrospective Cohort
Study. medRxiv; 2020. Available from: https://www.medrxiv. org/content/10.1101/2020.03.28.20046144v1.full.pdf. [Last accessed on 2020 May 02].

29. Huang C, Wang Y, Li X, Ren L, Zhao J, Hu Y, et al. Clinical features of patients infected with 2019 novel coronavirus in Wuhan, China. Lancet. 2020;395(10223):497-506. https://doi. org/10.1016/s0140-6736(20)30183-5

PMid:31986264

30. American Society of Hematology. COVID-19 and VTEAnticoagulation; 2020. Available from: https://www.hematology. org/covid-19/covid-19-and-vte-anticoagulation. [Last accessed on 2020 May 02]. https://doi.org/10.1016/j.htct.2020.05.002

31. Farkas J. Internet Book of Critical Care (IBCC): COVID19; 2020. Available from: https://www.emcrit.org/ibcc/ covid19/\#disseminated_intravascular_coagulation. [Last accessed on 2020 Apr 17].

32. Lin L, Lu L, Cao W, Li T. Hypothesis for potential pathogenesis of SARS-CoV-2 infection-a review of immune changes in patients with viral pneumonia. Emerg Microbes Infect. 2020;9(1):727-32. https://doi.org/10.1080/22221751.2020.1746199 PMid:32196410

33. Witt DM, Nieuwlaat R, Clark NP, Ansell J, Holbrook A, Skov J, et al. American Society of Hematology 2018 guidelines for management of venous thromboembolism: Optimal management of anticoagulation therapy. Blood Adv. 2018;2(22):3257-91. https://doi.org/10.1182/bloodadvances.2018024893 PMid:30482765

34. Lippi G, Plebani M, Henry BM. Thrombocytopenia is associated with severe coronavirus disease 2019 (COVID-19) infections: A meta-analysis. Clin Chim Acta. 2020;506:145-8. https://doi. org/10.1016/j.cca.2020.03.022

PMid:32178975

35. Wang J, Hajizadeh N, Moore EE, Mclntyre RC, Moore PK, Veress LA, et al. Tissue plasminogen activator (tPA) treatment for COVID-19 associated acute respiratory distress syndrome (ARDS): A case series. J Thromb Haemost. 2020;2020:14828. https://doi.org/10.1111/jth.14828

PMid:32267998 